\title{
Göstergebilimsel Analiz Üzerinden Tasarımı Anlamak: Sallanan At Üzerine
}

\author{
Understanding Design Through Semiotic Analysis: On Rocking Horse
}

\author{
Funda Kurak Açıcı ${ }^{\star} \oplus$, Havva Beril Bal ${ }^{\text {t* }}$ ๑
}

Öz

Sosyal yaşamın bir parçası olan iletişim, endüstri ürünlerinde de kendisini göstermektedir. Her tasarım ürününün taşıdığı bir anlam, ilettiği bir mesaj vardır. Ürünler iletişim işlevini biçimleri aracılığıyla gerçekleştirmektedir. Tasarım biçimi oluşturulurken ele alınan konsept fikir, tasarımın başkaları tarafından hissedilebilmesini sağlayan göstergesidir. Bu nedenle de tasarımı anlatırken, onun dilini aktarabilmek göstergebilimi bilmekle mümkün olmaktadır. Göstergebilim, ürünlerin iletişim işlevini yerine getirmesini sağlayan bir çözümleme imkanı sunmaktadır. Ürünlerin duyularla kavranmasında, algılanmasına ve anlamlandırılmasında göstergebilimsel ve anlambilimsel yaklaşımlara başvurulmaktadır. Tasarımın neye kime aktarılmak istendiği de göstergebilim açısından farklılık doğurmaktadır. Hedef kitle çocuk olduğunda; biçim ve anlatım dili de çocuğa yönelik şekillenmektedir. Oyun, çocuğun en etkili iletişim biçimidir. İlk çağlardan itibaren var olan oyun olgusu ve buna bağlı ortaya çıkan oyuncak, günümüzde teknoloji, malzeme, tüketim, kullanım alışkanlıkları gibi faktörlere bağlı olarak farklılaşmaktadır. Günümüzde eğitim aracı olarak da kullanılan oyuncakların anlamlandırılması bu bağlamda önem taşımaktadır. Bu çalışmada evrensel bir ürüne dönüşen oyuncağın genel anlamda ne ifade ettiği sorgulanarak göstergebilim üzerinden tasarım dili ortaya konulması amaçlanmaktadır. Bu amaca bağı olarak genellikle herkesin çocukluğunda deneyimleyebileceği bir oyuncak olan sallanan atın tasarım biçimi üzerinden göstergebilimsel çözümleme yapılmıştır ve ürünün görüntüsel, belirtisel ve simgesel anlamı tartışmaya açılarak, ortaya koyduğu anlam değerlendirilerek aynı oyuncak kategorisindeki farklı tipolojilerin ürün dili açısından karşılaştırması yapılmıştır.

\section{Anahtar Kelimeler}

Tasarım, Anlatım, Biçim, Gösterge, Oyuncak

\section{Abstract}

Communication is a part of social life and manifests itself in industrial products as well. Design products have meanings and messages. Products carry out communication through their own forms. The concepts taken into consideration while developing design forms are signs that make people feel them. It is, therefore, necessary to know about semiotics in order to convey the language of design Semiotics provides analysis and allows products to perform communication. Semiotic and semantic approaches play a role in the way senses perceive and interpret products. Semiotics differ according to what and to whom the design will be transferred. If the target audience is children, the form and language of expression should be determined according to them. Games are the most effective form of communication for children. The games and toys that have existed since early ages depend on factors such as technology, material, and consumption and usage habits.

* Sorumlu Yazar: Funda Kurak Açıcı (Doç. Dr.), Karadeniz Teknik Üniversitesi, Mimarlık Fakültesi, İç Mimarlık Bölümü, Trabzon, Türkiye. E-posta: fundaacici@ktu.edu.tr ORCID: 0000-0003-2592-2266

** Havva Beril Bal (Öğr. Gör.), Avrasya Üniversitesi, Mühendislik ve Mimarlık Fakültesi, İç Mimarlık ve Çevre Tasarımı Bölümü, Trabzon, Türkiye. E-posta: berilki@hotmail.com ORCID: 0000-0002-2347-3244

Atıf: Kurak-Acici, Funda ve Bal, Havva Beril. "Göstergebilimsel Analiz Üzerinden Tasarımı Anlamak: Sallanan At Üzerine." Art-Sanat, 13 (2020): 293-312. https://doi.org/10.26650/artsanat.2020.13.0012 
In this context, it is important to make sense of toys used as educational tools today. The aim of this study is to investigate the meaning of toys that are now universal products and to determine design language through semiotics. To that end, this study makes a semiotic analysis through the design of a rocking horse, a toy which almost everyone experiences in childhood. This study discusses and evaluates the icon, index and symbol of the rocking horse and compares the product language of different typologies in the same toy category.

Keywords

Design, Expression, Form, Sign, Toy

\section{Extended Summary}

Communication is a part of social life and manifests itself in industrial products as well. Design products have meanings and messages. Products carry out communication through their own forms. Form allows designers to express their products and allows products to be recognized and evaluated by users. The concepts taken into consideration while developing design forms are signs that make people feel them. The symbols of designs are transmitted to users through an iconic language, and such design elements as texture, material, form, line and color facilitate communication. It is, therefore, necessary to know about semiotics in order to convey the design language. Semiotics provides analysis and allows products to perform communication. Semiotic and semantic approaches play a role in the way senses perceive and interpret products., Although semiotics and semantics are used as effective analysis techniques in the field of design, they should provide the basis for today>s user-oriented approaches as well. Semiotics differ according to what and to whom design will be transferred. If the target audience is children, the form and language of expression should be determined according to them.

Games are the most effective form of communication for children. The games and toys that have existed since early ages depend on factors such as technology, material, consumption and usage habits. Children have the opportunity to recognize living or non-living beings through interaction with toys and construct experiences in their own world. In this context, it is important to make sense of toys used as educational tools today. The aim of this study is to investigate the meaning of toys that are now universal products and to determine design language through semiotics. To that end, this study makes a semiotic analysis through the design of rocking horse, a toy which almost everyone experiences in childhood. This study discusses and evaluates the icon, index and symbol of the rocking horse and compares the product language of different typologies in the same toy category. The study consists of three stages. In the first stage, rocking horse images were obtained, similar images were eliminated, and 48 models were identified. Afterwards, ten horse models were selected for analysis. In the second stage, a questionnaire was applied to a group of 37 children aged 3-6 years to determine what the ten horse models meant for users. Participants were asked if they wanted to have the toys and what they thought the toys looked like. In the third 
stage, semiotic analysis was used. The horse models were first analyzed using the sign system developed by Charles Sanders Peirce and used by O-Neill in product analysis. Peirce's icon, index and symbol were classified by O'Neill. According to O'Neill's classification, icon is form tradition, color, material, metaphor, style and environment; index is form, light and sound, noise, smell, touch and graphs, and symbol is graphical symbols, symbolic colors and symbolic forms. The rocking horse has a certain sound, which varies according to the ground on which the toy stands. Semiotics does not involve experience, and therefore, this study ignored material odor and excluded such signs as light, sound, noise and odor from analysis.

The form tradition, which is a visual sign, is defined as abstract and concrete expression. Forms that have a clear resemblance to objects are described as concrete and others as abstract. The survey results support this definition and form the basis for analysis. Color, material, style and environment were interpreted by the authors. The horse models were made of bent and/or cut sheet material, and therefore, their style signs were defined as modern. As for environment, a description was made for each interior. Metaphor data were obtained from surveys. Repetitive responses were used for analysis. In this context, the fact that the shape of the toy was abstract led to the diversification of similar objects. Participants mostly expressed such vehicles as car, motorcycle and sled, such objects such as gear, seesaw, swing and bed, and lamb, moon, cloud and various animals.

Pointing, touching and graphic shapes, which are index types, were also interpreted by the authors. Participants did not have the opportunity to experience the models and to express them through photographs, and therefore, the authors did the interpretation. The results showed that all products indicate forms of usage.

The authors used the participants' survey responses to determine symbolic format, graphic icon, and symbolic color. The results showed that the symbolic colors on the horse models are usually used to highlight the functions of holding, resting, and sitting. The colors on some models caused participants to be reminded of different things (such as blue-wave; black - crow). Participants generally associated the forms of the horse models with rocking, riding, lying down and sitting, indicating the symbolic form of the product.

In conclusion, the rocking horse toy that transforms into different forms holds significant meaning, enabling children's imagination to be increased through its different formal meanings as long as it is in children's lives. 


\section{Giriș}

Endüstri ürünleri tasarlanma sürecinde hem işlevsel olarak kullanıcıya hizmet verebilmeyi amaçlamakta hem de kullanıcıyla iletişim kurmaktadır. Her ürün bir mesaj iletmektedir. Bu sayede kullanıcısı tarafından anlamlandırılmaktadır. Tasarım çeşitli göstergelerden oluşmaktadır ve ürünleri anlamlandırabilmek, bu göstergelere bağlı analizlerle mümkün olmaktadır. Tasarımın neye, kime aktarılmak istendiği de göstergebilim açısından farklılık göstermektedir. Örneğin hedef kitle, çocuk olduğunda biçim ve anlatım dili de çocuğa yönelik şekillenmektedir. Oyuncaklar, oyun türüne ve yaşına göre şekillenen, çocuk için en etkili iletişim biçimi olan oyun materyalleridir. Çocuğun hayal gücüne bağlı olarak farklı anlamlara, işlevlere veya formlara bürünebilmektedir. Günümüzde oyuncaklar, çocuğun yaratıcılığını destekleyecek, hayal gücünü artıracak niteliklerde olmanın yanı sıra eğitim aracı olarak da kullanılmaktadır. Çocuklar, oyuncaklarla kurdukları ilişkiler sonucunda, canlıları, nesneleri, figürleri tanıma firsatı bulabilmekte ve edinilen birikimleri kendi dünyalarında kurgulayabilmektedir. ${ }^{1} \mathrm{Bu}$ nedenle oyuncağın anlamlandırılması önem taşımaktadır.

Ürünlerin duyularla kavranmasında, algılanmasında ve anlamlandırılmasında göstergebilimsel ve anlambilimsel yaklaşımlara başvurulmaktadır. Göstergebilim ve anlambilim, tasarım alanında yetkin bir analiz aracı kullanılsa da günümüzdeki kullanıcı odaklı yaklaşımlara zemin teşkil etme gerekliliği de bulunmaktadır. Krippendorff tasarımı "şeyleri anlamlı yapma etkinliği”’’ olarak tanımlamıştır. Tasarımda anlamın kime ait olduğu kullanıcı odaklı tasarıma yakın bir anlayışı ifade etmektedir. ${ }^{3}$ Tasarımın neye ve kime aktarılmak istendiği de göstergebilim açısından farklılık göstermektedir.

Bu çalışmada evrensel bir ürüne dönüşen oyuncağın genel anlamda ne ifade ettiği sorgulanarak göstergebilim üzerinden tasarım dilinin ortaya konulması amaçlanmaktadır. Bu amaca bağlı olarak genellikle herkesin çocukluğunda deneyimleyebileceği bir oyuncak olan sallanan atın tasarım biçimi üzerinden göstergebilimsel çözümlemesi yapılmıştır ve ürünün görüntüsel, belirtisel ve simgesel anlamı tartışmaya açılarak, ortaya koyduğu anlam değerlendirilmiş ve aynı oyuncak kategorisindeki farklı tipolojilerin ürün dili açısından karşılaştırması yapılmıştır.

Çalışma üç aşamalı olarak gerçekleştirilmiştir. Birinci aşamada literatürde yer alan Sallanan At oyuncağına dair görsellere ulaşılmıştır. Elde edilen sallanan at örneklerinden benzer modeller elenmiş ve yapılan elemeler sonucunda belirlenen 10 at modelinin analizinin yapılmasına karar verilmiştir. İkinci aşamada seçilen ürün grubunun kullanıcı için ne ifade ettiğinin belirlenmesi amacıyla 3-6 yaş arası çocuklardan oluşan

1 Tosun Yalçınkaya, Eğitici Oyun ve Oyuncak Yapımı (İstanbul: Esin Yayınevi, 2004), 40.

2 Klaus Krippendorff, Content Analysis: An Introduction to Its Methodology (Pennsylvania: Sage Publications, 1989), 91.

3 Hümanur Bağl1, "Product Semantics Meet The User: A Design Workshop with a Fresh Look to an Old Paradigm," ITU AZ Journal 8 (2011), 120. 
37 kişilik gruba anket uygulanmıştır. Çalışmanın üçüncü aşamasını göstergebilimsel analiz çalışması oluşturmaktadır. Belirlenen 10 sallanan at modeli, ilk olarak Charles Sanders Peirce'in ${ }^{4}$ geliştirdiği ve $O^{\prime}$ Neill' 'in ${ }^{5}$ ürün analizinde kullandığı gösterge sistemi üzerinden analiz edilmiştir.

\section{Tasarım ve İletişim}

Temelde iletişim süreci, bir verici tarafından oluşturulan mesajın bir kanal aracılığıyla tanımlı bir alıcıya iletilmesi ve alıcıda bir tepki oluşturulması olarak tanımlanmaktadır. Tasarımda iletişim süreci ise bilginin taşıyıcısı olan ürünün kendisiyle gerçekleşmektedir. Tasarımda özne, ürün biçim sistemi olarak adlandırılmaktadır. Özne, toplumun ortak biçim dili dağarından seçilmiş biçim nitelikleri ile kodlanmış bir sistem kanalıyla kullanıcı ile iletişim kurmaktadır. Kullanıcı ise kodlanmış biçim niteliklerini ürün üzerinden okuyarak mesajı anlamlandırmaktadır. Biçimin anlamlandırılması ve yanıtlanması sonucu iletişim gerçekleşmiş olur. ${ }^{6}$ (G. 1)

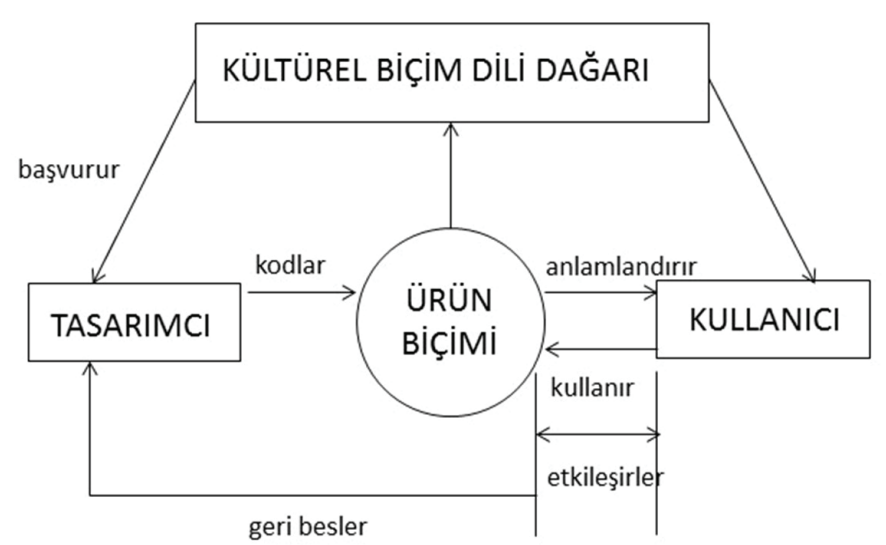

G. 1. Tasarımda iletişim (Turan, Tasarımda İletişim Sürecinin Oturma Elemanları Üzerinden Irdelenmesi, 23)

İletişim süreci nesnenin alıcı tarafından seçildiği andan itibaren başlayıp nesnenin kullanım sürecinde devam etmektedir. Endüstri ürünleri, sahip oldukları kullanım işlevlerinin karşılığı olarak algılanarak, onların birer anlam aktarıcısı ya da iletişimin taşıyıcısı olduğu gerçeği göz ardı edilmektedir. Oysa nesnenin kullanım işlevini kar-

4 Charles Sanders Peirce, Peirce on Signs: Writings on Semiotic, der. James Hoopes (North Carolina: The University of North Caroline Press, 1994).

5 Shaleph O'Neill, Comparing Compatible Semiotic Perspectives for the Analysis of Interactive Media Devices (Londra: Springer, 2005).

6 Ahmet Zeki Turan, “Tasarımda İletişim Sürecinin Oturma Elemanları Üzerinde İrdelenmesi” (Yüksek lisans tezi, İstanbul Teknik Üniversitesi, 2001), 22. 
ş1lamas1, kullanış1 olması ya da ergonomik olması, her endüstri ürününde bulunması gereken, nesnenin olmazsa olmaz koşuludur. Gerçekte kullanıcının ürün seçimlerinin dayanağı, iletişimsel işlevler dediğimiz ürünün ne olduğuna özgü anlamlandırmalardır. Hiçbir anlam taşımıyormuş gibi görünen bir ürün bile, en azından "hiçbir anlam taşımama" anlamını iletmektedir. ${ }^{7}$ Nigan Bayazıt nesnenin anlam taşıyıcılığını şu şekilde belirtir:

"Fiziksel bir nesnenin biçimi bir fikir grubunun ya da bir grup fikrin bir temsilcisidir. Bu fikirler sistemler konusunda temel genellemelere öncelik eden gösterge bilimciler tarafindan tanımlandı̆̆g zaman, iletişsim sistemine dönüşürler. Amaç olarak bütün iletişim sistemleri bir insan zihninden diğerine, anlamın mesajının taşlyıcısına sahiptir. Anlamsız, fikirsiz hiçbir mesajın içeriği yoktur. Illetişim sistemleri konusunda mesaj tasarımcının tasarlamakta olduğu nesne konusundaki fikri ya da fikirleridir. Bu fikirler tasarımcının başkaları tarafindan hissedilebilecek gerçeklik olarak seçtiği biçimler yoluyla ifade edilir." 8

Endüstri ürünlerinin biçimi, tasarımcının sahip olduğu kültürel dağarcığa bağlı olarak şekillenmekte ve iletişim işlevini sahip oldukları bu biçimler karşılamaktadır. Ürün biçimi tasarımcının iletmek istediği mesajı iletirken, bu sayede kullanıcısının ürünü anlamlandırmasını da sağlamaktadır. Tasarımda iletişim sürecinin çözümlenebilmesinde çağdaş iletişim bilimleri olan Dilbilim, Göstergebilim ve Anlambilimden faydalanılmaktadır. ${ }^{9}$ Göstergebilimin temelleri her ne kadar antik çağa kadar uzansa da günümüz anlayışı 20. yüzyıl düşünürleri Saussure ve Peirce'in çalışmalarına dayalı olarak şekillenmiştir. Göstergebilimin tasarım alanında incelenmesiyse ürün anlambiliminin isim babası Krippendorf tarafından gerçekleştirilmiştir. ${ }^{10}$

Tasarımın ve iletişimin tasarım dilini aktardığı öngörüldüğünde, göstergebilimden yararlanmadan tasarım dilini aktarmanın mümkün olmadığı da açıktır.

\section{Göstergebilim}

Göstergebilim, kültürü iletişim açısından inceleyen bilim dalı olarak tanımlanmaktadır. Gösterge ise kendisi o şey olmadığı halde, o şeyi çağrıştırarak iletişim sağlayan bir birimdir. ${ }^{11}$ Diğer bir deyişle kişiye bir mesaj ileten, bildiği bir şeyi çağrıştıran ya da yorum yapmasını sağlayan iletişim elemanıdır.

Endüstri ürünleri, kültürel, sosyal gerçeklikleri nedeniyle anlam taşıyıcı biçimlerdir. Bu özelliğiyle ürün, bir gösterge olarak, göstergenin tüm niteliklerini taşır. Ürünün

7 Oğuz Bayrakçı, "Göstergebilimsel Araştırma Alanı Olarak Ürün Tasarımı,” Tasarım Kuram Dergisi, (2011), 2.

8 Nigan Bayazıt, Tasarımı Anlamak (İstanbul: İdeal Kültür Yayınevi, 2008), 328.

9 Bayrakçı, "Göstergebilimsel Araştırma Alanı Olarak Ürün Tasarımı," 2.

10 Bkz. Krippendorff, Content Analysis: An Introduction to Its Methodology, 1989.

11 Fatma Erkman, Göstergebilime Giriş (İstanbul: Alan Yayıncılık, 1987), 22. 
biçimi ya da biçim nitelikleri gösterenin/gönderenin bir taşıyıcısı veya tarzına ilişkin bir özelliktir. Biçim, nesneye gönderme yapan bir araçtır. Biçim nesneye değişik yollarla gönderme yaptığı gibi nesnenin değişik türlerine de gönderme yapar. ${ }^{12}$ Ürün göstergesinin göstereni biçim ve biçim özellikleri; gösterileni ise ürünün kullanım işlevi ve ona eklenen kültürel sosyal olgulardan meydana gelmektedir. Bir gösterge olarak her ürün, biçimi aracılığıyla işlevine gönderme yapmaktadır.

Göstergebilime ait iki anlam modeli göze çarpmaktadır. Bu modeller Pierce ve Saussure tarafından ortaya konmuştur. Saussure açısından gösterge, bir kavramla onun dışavurum biçiminden oluşmaktadır. Saussure'un göstergesi ikili bir yapıdadır ve biçimi gösteren, içeriği ise gösterilen kavram çiftiyle ifade edilmektedir. Pierce'in göstergesiyse üç düzlemlidir. Pierce'e göre, somut biçimini algılamakla, onun neyi temsil ettiğini anlamak arasına bir yorum süreci girmektedir. ${ }^{13}$ (G. 2)
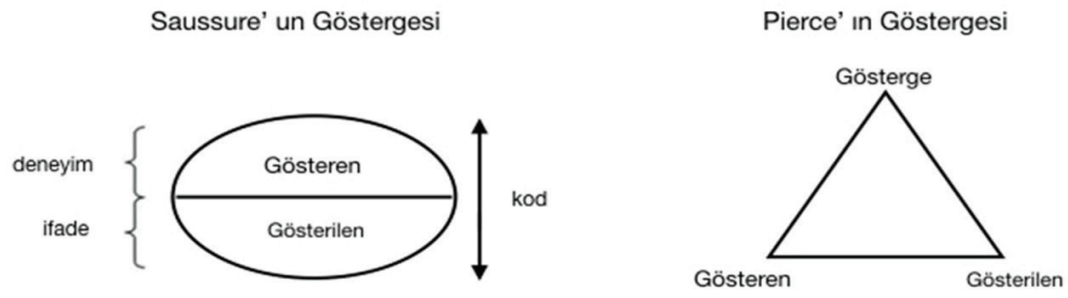

G. 2. Saussure ve Pierce'ın göstergeleri (Bayrakçı, Göstergebilimsel Araştırma Alanı Olarak Ürün Tasarımı, 4)

Pierce, göstergeleri üçlü ilişkilere dayalı olarak, 10 ayrı üçlükte topladığı 30 türe ayırarak sınıflandırmıştır fakat ürün göstergesini en çok ilgilendiren gösterge tipleri Belirti (Index), Görüntüsel Gösterge (Icon), Simge (Symbol) kavramları üstünde temellenerek geliştirilmiştir. ${ }^{14}$ (T. 1)

Tablo 1. Tasarımda Gösterge Türleri ve Özellikleri (Bayrakçı, Göstergebilimsel Araştırma Alanı Olarak Ürün Tasarımı, 6)

\begin{tabular}{|c|c|c|c|}
\hline \multicolumn{4}{|c|}{ TASARIM ALANINDA KULLANILAN GÖSTERGE TÜRLERİ VE ÖZELLIKLERİ } \\
\hline GÖSTERGE TÜRLERİ & $\begin{array}{c}\text { OLUŞUM } \\
\text { BAĞLANTISI }\end{array}$ & KULLANIM BAĞLANTISI & $\begin{array}{c}\text { İLETIŞìM } \\
\text { BAĞLANTISI }\end{array}$ \\
\hline Belirti (indeks) & Nedenli & Öğrenmeye dayalı & Niyetsiz \\
\hline Görüntüsel (ikon) & Nedenli & Benzerlik ilişkisine dayalı & Niyetli \\
\hline Simge (sembol) & Nedensiz & Uzlaşmaya dayalı & Niyetli \\
\hline
\end{tabular}

12 Susann Vihma, "Product Form-A Semiotic Approach. Semantic Visions in Design," Symposium on Design Research and Semiotics, 1990.

13 Erkman, Göstergebilime Giriş, 28.

14 Bayrakçı, "Göstergebilimsel Araştırma Alanı Olarak Ürün Tasarımı,” 5. 
Görüntüsel gösterge, gönderme yaptığı nesneyi çağrıştırmak için benzerlik alanında yeterli ipuçları taşıyan gösterge olarak tanımlanmaktadır. ${ }^{15}$ Başka bir deyişle görüntüsel gösterge, nesnesiyle benzeşim ilişkisi kurmaktadır. ${ }^{16}$ Form geleneği, ürünlerin zaman içinde oluşturdukları ve sahip oldukları biçimlerle bu form geleneğine gönderme yapmalarıyla ifade edilirken; renk ve malzemeyle başka bir nesne alanına ait anlama gönderme yapabilir. Bir ürün biçimi sahip olduğu metaforla tamamen farklı bir ürün biçimine gönderme yaparken aynı zamanda bir stile ait biçimlere de gönderme yapabilir. Ayrıca bazı ürünlerin belirli çevrelere göre tasarlanmış olmaları bu çevreye gönderim yapmasını sağlamaktadır. ${ }^{17}$

Belirtisel göstergeler ise biçimle işlev arasında bağlantı kurulmasını sağlamaktadır. İşaretleme biçimi, ürünün kendisinin işlevini ifade eden bir forma sahip olması şeklinde açıklanabilir. Işık ve ses göstergesi genelde elektronik ürünlerde görülürken, koku ve dokunma göstergesi malzeme özelliğiyle var olabilir. Fakat ürünün niteliğine bağl1 olarak kendi içinde tüm belirtisel göstergeleri de taşıyabilirler. Grafik şekiller ise yine ürünün üzerinde yer alan ve işlevini belirtmeye yarayan göstergelerdir. ${ }^{18}$

Simgesel göstergeler göstergenin alıcısında kendinden başka bir nesne hakkında belirli bir duygu ya da düşünce uyandırmaktadır. Grafik simgeler, üründe yer alan logo, yazı, açma- kapama düğmeleri olup simgesel renkler, rengin sahip olduğu yan anlamla ilişkilidir. ${ }^{19}$

Pierce'in görüntüsel, belirtisel ve simgesel gösterge türlerine bağl1 göstergebilimsel analizi birçok çalışmada kullanılmıştır. Hümanur Bağlı, tez çalışmasında zanaat ve tasarım kavramları tarafından ve turizm örneği üzerinden temsil edilen zaman, mekan, işlev, üretim kavramlarını Pierce'ın gösterge türleri üzerinden analiz etmiştir. ${ }^{20}$ Ayrıca Hümanur Bağlı, başka bir çalışmasında Peirce'in görüntüsel, belirtisel ve simgesel gösterge kavramlarını analiz aracı olarak değil, ele alınan bir ürün üzerinde bir değişken ve yeni bir ürün fikrinin temeli olarak kullanmıştır. ${ }^{21}$ Önder Erkarslan ise "sürdürülebilir" ve "yeşil" etiketli ürünlerin piyasanın arzına sunulurken kullanılan kategorilerin geçerli olup olmadıklarını açığa çıkarmak ve bu yolla eleştirel bir yaklaşım geliştirmek amacıyla göstergebilimsel analizden faydalanmıştır. ${ }^{22}$

15 Umberto Eco, Function and Sign: The Semiotic of Architecture. Sign, Symbol and Architecture, ed. Broadbent, G., Bunt, R., Jencks, C., (New York: John Willey and Sons, 1979), 182.

16 Hümanur Bağlı, “Temsil Araçları Olarak Zanaat ve Tasarım: Turistik Nesneler Üzerine Kavramsal Bir Analiz," (Doktora tezi, İstanbul Teknik Üniversitesi, 2001), 88.

17 O'Neill, Comparing Compatible Semiotic Perspectives for the Analysis of Interactive Media Devices, 70.

18 O'Neill, Comparing Compatible Semiotic Perspectives for the Analysis of Interactive Media Devices, 71

19 Eco, Function and Sign: The Semiotic of Architecture. Sign, Symbol and Architecture, 183.

20 Hümanur Bağlı, "Temsil Araçları Olarak Zanaat ve Tasarım: Turistik Nesneler Üzerine Kavramsal Bir Analiz," 88-116.

21 Hümanur Bağlı, "Ürün Tasarımı Eğitiminde Kuram ve Uygulamanın Kesișmesi: Anlambilimsel Bir Deneme" UTAK 2014 Bildiri Kitabı, der Pınar Kaygan, Harun Kaygan (Ankara: ODTÜ Mimarlık Fakültesi Basım İşliği, 2014).

22 Önder Erkarslan, "Yeşil-Yeşilimsi: Ürün Göstergebilimi Aracılığıyla Sürdürülebilir Tasarım Uygulamaları- 
Vihma, ürün göstergebilimi konusunda çeşitli çalışmalar yapmıştır ve yönteminde, öncelikle ürünün iskeletini oluşturan yapıyı parçalamış, sonra tasarım ürününün parçalarını işlevsel açıdan eklemlemeye çalışmıştır. ${ }^{23}$ Pierce'ın gösterge sınıflarının alt bölümlerini yirmi işlev sembolüyle somutlaştırmıştır.

O’Neill ${ }^{24}$ ise ürün göstergebilimini yöntem olarak benimsediği çalışmasında Vimha'nın ortaya koyduğu gösterge tiplerinden endüstri ürünleriyle ilgili olanları ele alarak ürünleri analiz etmiştir. (T. 2)

Tablo 2. Gösterge Türleri (O’Neill, Comparing Compatible Semiotic Perspectives for the Analysis of Interactive Media Devices, 111)

\begin{tabular}{|l|l|l|}
\hline \multicolumn{2}{|c|}{ Gösterge Türleri } \\
\hline Görüntüsel & Belirtisel & Simgesel \\
\hline Form geleneği & İşaretleme biçimleri & Grafik simgeler \\
\hline Renk & Işsk ve Ses & Simgesel renkler \\
\hline Materyal & Gürültü & Simgesel biçimler \\
\hline Metafor & Koku & \\
\hline Tarz & Dokunma & \\
\hline Çevre & Grafik şekiller & \\
\hline
\end{tabular}

Çalışmanın bu bölümünde genel olarak, göstergebilime giriş yapılmış ve gösterge türleri üzerinde durulmuştur. Buradaki amaç, çalışmanın devamında seçilen oyuncak üzerinden göstergebilimin sorgulanabilmesi için bir alt yapı oluşturulmasıdır. Gösterge türlerinden görüntüsel, belirtisel ve simgesel gösterge, seçilen oyuncak modelleri üzerinden değerlendirilmektedir.

\section{Oyun ve Oyuncak Kavramı}

Oyun, genellikle gerçek dünya dışında, kesin olmayan, kendine özgü kuralları ve kültürü olan, eğlenceli ve isteğe bağlı bir etkinliktir. ${ }^{25}$ Çocukluktaki en yüksek dışavurum olan oyun, çocuğun en etkili iletişim biçimidir. Çocuğu hayata hazırlarken doğal ve aktif öğrenmeye imkan verir. ${ }^{26}$ Oyun oynamak Yavuzer'e göre, çocuğun birçok şeyi kendi deneyimleriyle öğrenmesini sağlarken yeteneklerini geliştirmekte ve çocuğa özgürlük kazandırmaktadır. ${ }^{27}$ Çocuk oyun sayesinde içinde yaşadığı kültürün önemli

nın Eleştirisi”, Mimarlk Dergisi 349, (Eylül-Ekim 2009), erişim 2 Kasım 2018 http://www.mimarlarodasi. org.tr/mimarlikdergisi

23 Erkarslan, "Yeşil-Yeşilimsi: Ürün Göstergebilimi Aracılı̆̆ıyla Sürdürülebilir Tasarım Uygulamalarının Eleştirisi," erişim 2 Kasım 2018

24 O'Neill, Comparing Compatible Semiotic Perspectives for the Analysis of Interactive Media Devices, 117-126.

25 Deniz Yengin ve Tamer Bayrak, "Tüketimin Oyunlaştırılmasıyla Artırılmış Gerçeklik," Etkileşim Dergisi 1 (2018), 62.

26 Şengül Yalçınkaya, "Modern Kentin Yeni Kamusal Alanında Çocuk, Alışveriş Merkezleri ve Serbest Zaman Etkinlikleri," Idealkent Dergisi 17 (2015), 94.

27 Haluk Yavuzer, Çocuk Psikolojisi (İstanbul: Remzi Kitabevi, 2016), 177. 
etkilerinden olan araştırma duygusunu ve kurallara uymayı öğrenmekte ve geliştirmektedir. Çocuk oyun oynarken genellikle oyundaki rolüne uygun gerçek bir nesne ya da bu nesnenin yerini alacak bir eşyaya ihtiyaç duymaktadır. Oynayıp eğlenmeye yarayan ya da oyuna göre değişen niteliklere sahip olan şey olarak tanımlanan oyuncak, çocuğun dış dünyayı tanımlayabilmesine ve ona anlamlar katmasına yardımcı olmaktadır. ${ }^{28}$ Yavuzer ise oyuncağı çocuğun oyununu gerçekleştirmesi için, kullandığı her türlü araç olarak tanımlanmaktadır. ${ }^{29}$ Oyuncak, çocuğun doğal yeteneklerini kolaylaştıran, böylelikle de büyük bir eğitimsel işlevi yerine getiren, oyunda kullanılan malzemedir. Gelişim basamakları boyunca çocuğun hareketlerine düzen getirirken, zihinsel ve bedensel gelişimlerine yardımcı olmaktadır. Ayrıca çocuğun yaratıcı yeteneklerini geliştirmeye katkı sağlamaktadır. ${ }^{30}$ Oyun yoluyla öğrenmeyi sağlayan ve oyuna ek olan oyuncaklar, sosyal ve kişisel gelişimi sağlamaya yardımcıdır. Çocukların, arkadaşlarıyla birlikte aynı oyuncaklarla oynayabilmeleri ve oyuncaklarını paylaşabilmeleri neticesinde sosyal gelişim sağlanmaktadır. ${ }^{31}$ Oyuncaklar hayal gücünün gelişmesi, renk, boyut ve şekillerin algılanması, sayısal ve yazınsal kavramların öğrenilmesi gibi konularda çocukların gelişimine katkıda bulunmaktadır. ${ }^{32}$ Böylelikle oyuncaklar yeni keşiflere yol açarken, çocuğu eğlendirmenin yanında kendi başına karar verebilmesini ve seçme değerlendirme duygusunun gelişmesini sağlamaktadır. ${ }^{33}$

Oyuncak seçiminde oyuncağın çocuğun yaşına, gereksinimlerine, yetenek ve ilgilerine uygun olması önem taşımaktadır. Seçim için çocuğun iyi tanınması, gelişim aşamalarıyla bu aşamaların özelliklerinin ve oyun evrelerinin iyi bilinmesi gereklidir. $\mathrm{Bu}$ nedenle gelişim alanlarına göre oyuncakların kategorizasyonu çok önemlidir.

Büyük kas gelişimini destekleyici bir oyuncak olan sallanan at çocuğu hareket etmeye teşvik eden bir aktivite oyuncağıdır. Çocukta denge ve harekette esneklik sağlarken çocuğun psiko-motor gelişimine katkıda bulunmaktadır. Güntürkün, oyuncakları çocukların gelişim alanlarına göre sınıflandırmış ve sallanan atı kaba motor becerilerini destekleyen oyuncaklar içinde yer vermiş ve yaş aralığını $1.5-2.5$ yaş arası olarak belirtmiştir. ${ }^{34}$ Yalçınkaya'nın sınıflandırmasına göre sallanan at $2-2,5$ yaş arası çocuklara hitap eden bir oyuncak olarak kategorize edilmiştir. ${ }^{35}$ Tarihsel sürece bakıldığında oyuncakların eski çağlardan beri var olduğunu söylemek mümkündür. At

28 Esin Düzakın ve Emre Güntürkün, "Yapı Oyuncaklarının Tarihsel Gelişimi," Marmara Üniversitesi Sanat Tasartm Dergisi 8 (2017), 35.

29 Yavuzer, Çocuk Psikolojisi, 183.

30 Yavuzer, Çocuk Psikolojisi, 185.

31 Düzakın ve Güntürkün, "Yapı Oyuncaklarının Tarihsel Gelişimi," 35.

32 Yavuzer, Çocuk Psikolojisi, 185.

33 Naim Ünver, "Kastamonu İl Merkezinde Yaşayan 0-2 Yaşları Arasında Çocuğa Sahip Anne-Babaların Çocukları İçin Oyuncak Satın Alma Durumları ve Tercihlerinin İncelenmesi” (Yüksek lisans tezi, Gazi Üniversitesi, 2005), 55 .

34 Düzakın ve Güntürkün, "Yapı Oyuncaklarının Tarihsel Gelişimi,” 36.

35 Yalçınkaya, Eğitici Oyun ve Oyuncak Yapımı, aktaran Aydın, Oyuncak tasarımında Sürdürülebilirlik Esaslarının Uygulanması, 16. 
figürü, farklı kullanım şekilleriyle oyuncak olarak tarihte yer almıştır. İlk olarak MÖ 5. yüzyılda Mısırlı çocukların tekerlekli küçük tahta atlarla oynadıklarına dair arkeolojik bilgiler edinilmiştir. ${ }^{36}$ Antik Yunan'da bulunan oyuncaklar arasında yer alan at, bu dönemde değnek at biçimini almıştır. Tahta ata binen çocuklar ilk kez 17. yüzyılın gravürlerinde görünmeye başlamıştır. Değnek at bu dönemde de varlığını sürdürmüştür. Tahta atın oyuncaklar arasında sürekli yer alması atın geçmiş zamanlarda, şimdi otomobilin olduğu gibi, çok önemli olduğunu açıkça göstermektedir. ${ }^{37}$ Değnek at, ata binmekle bağdaştırılarak ortaya konmuş bir biçimdir. Daha sonra binmek işlevine sallanma işlevi eklenmiştir (G.3.).

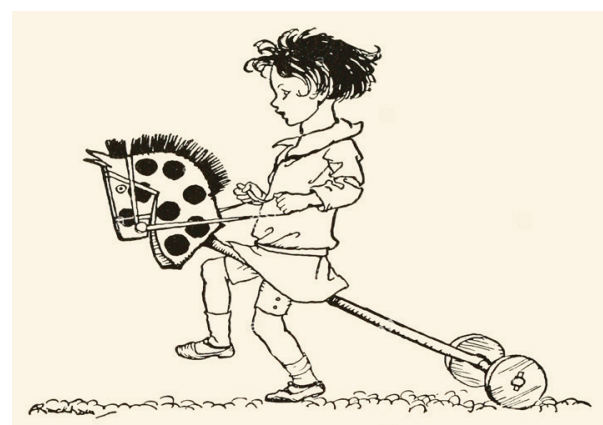

G. 3. Değnek at (https://www.agefotostock.com/age/en/Stock-Images/Rights-Managed/MEV10508234)

\section{Yöntem}

Oyuncaklar, bir açıklama olmaksızın, çocukların anlayabileceği nesnelerdir. Oyuncaklar, her çocuk tarafından aynı amaçla, farklı şekillerde kullanılma potansiyeli taşımaktadır. ${ }^{38}$ Tüm hareketli parçalar, keşfedilecek beklenmedik şekillerin veya hareketlerin dizilimini arttırır. ${ }^{39}$ Çocuklar, oyuncaklarla girdiği etkileşim sonucunda çevresinde yer alan canlı ve cansız varlıkları tanıma firsatı bulabilmekte ve bu birikimleri de kendi dünyasında kurgulayabilmektedir. Günümüzde eğitim aracı olarak da kullanılan oyuncakların anlamlandırılması bu bağlamda önem taşımaktadır ve çalışmada evrensel bir ürüne dönüşen oyuncağın genel anlamda ne ifade ettiği sorgulanarak göstergebilim üzerinden tasarım dili ortaya konulması amaçlanmaktadır. Bu amaca bağlı olarak genellikle herkesin çocukluğunda deneyimleyebileceği bir oyuncak olan sallanan atın tasarım biçimi üzerinden göstergebilimsel çözümlemesi yapılmıştır ve ürünün görüntüsel, belirtisel ve simgesel anlamı tartışmaya açılarak,

36 Rüşvanlı, “Türkiye'deki Oyuncak Sektöründe Yeni Ürün Tasarımını Tetikleyen Faktörler,” 10.

37 Bekir Onur, "Tarih Boyunca Oyun ve Oyuncaklar”, Ankara Üniversitesi Eğitim Bilimleri Fakültesi Dergisi 2, (1992), 367.

38 Nur Cinel Özyeşer, "Farklı SosyoEkonomik Düzeydeki 3-6 Yaş Grubu Çocuğu Olan Anne-Babaların Oyuncak ve Oyun Materyalleri Hakkındaki Görüşlerinin ve Bu Yaş Grubu Çocukların Sahip Oldukları Oyuncak ve Oyun Materyallerinin İncelenmesi”" (Yüksek Lisans Tezi, Gazi Üniversitesi, 2006), 10.

39 P. Ambeck Madsen, “Toys and Play,” The Danish Design Center Magazine 4 (1995), 3-20'den aktaran Düzakın ve Güntürkün, "Yapı Oyuncaklarının Tarihsel Gelişimi," 36. 
ortaya koyduğu anlam değerlendirilmiş ve aynı oyuncak kategorisindeki farklı tipolojilerin ürün dili açısından karşılaştırması yapılmıştır. Çalışma üç aşamalı olarak gerçekleştirilmiştir. Birinci aşamada Sallanan At oyuncağına dair literatür taraması ve internet araştırması yapılmıştır. Öncelikle Türkiye'den örnekler araştırılmış fakat araştırma sırasında birbiriyle aynı ürünlere rastlanmıştır. Bu nedenle araştırmanın kapsamı Türkiye’yle sınırlandırılmamıştır. Türkçe "sallanan at", İngilizce "rocking horse" anahtar kelimeleriyle arama yapılmıştır. Yapılan araştırmalarda genellikle satış sitelerine ulaşıldığından oyuncakların yapım yıllarına ulaşılamamıştır. Yapılan tarama neticesinde 160 ürün tespit edilmiştir. Elde edilen sallanan at örneklerinden benzer modeller elenmiş ve 48 adet farklı model seçilmiştir. (T. 3).

Tablo 3. 48 Adet Farklı Sallanan At Modeli

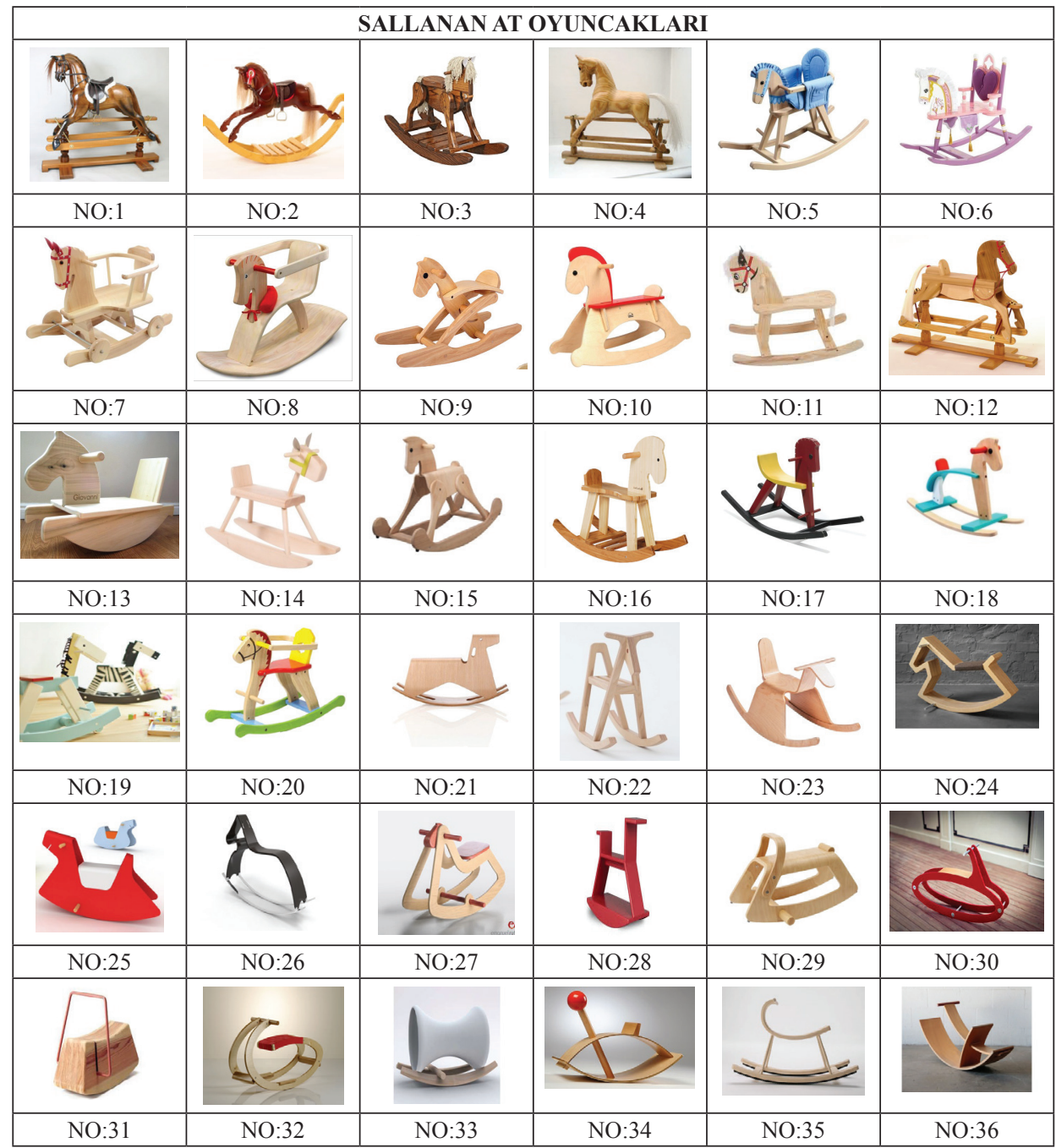




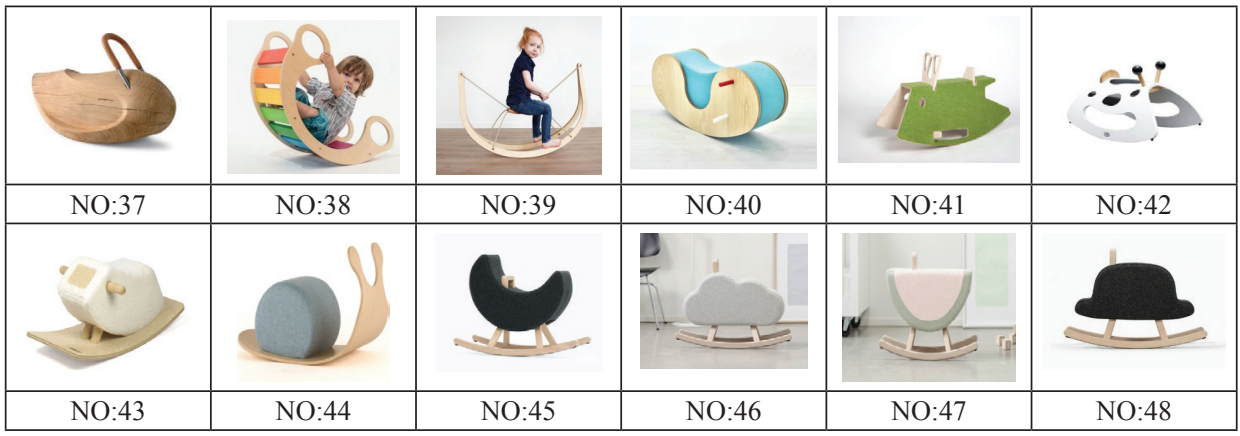

Yapılan elemeler sonucunda 48 model at içinden belirlenen 10 model atın analizinin yapılmasına karar verilmiştir. (T. 4)

Tablo 4. Analiz Edilecek Sallanan Atlar

\begin{tabular}{|c|c|c|c|c|}
\hline \multicolumn{5}{|c|}{ SALLANAN ATLAR } \\
\hline NO: 24 & NO: 27 & NO: 29 & NO: 32 & NO:34 \\
\hline NO: 36 & NO: 40 & NO: 43 & NO:45 \\
\hline
\end{tabular}

İkinci aşamada belirlenen ürün grubunun kullanıcı için ne ifade ettiğinin tespiti amacıyla 3-6 yaş arası çocuklardan oluşan 37 kişilik bir gruba anket uygulanmıştır. (T. 5) Çocuklara 10 adet sallanan at oyuncağının fotoğrafı gösterilmiş ve daha sonra sorular yöneltilmiştir. Anket okul ortamında öğretmenler tarafından uygulanmıştır. Çocuklara gördükleri oyuncağa sahip olmayı isteyip istemedikleri ve gördükleri oyuncağı neye benzettikleri sorulmuştur.

Tablo 5. Anket Uygulanan Katılımcı Özellikleri

\begin{tabular}{|l|l|l|}
\hline Katılımcı profili & Grup & \% \\
\hline \multirow{3}{*}{ Cinsiyet } & Kız & 51.4 \\
\cline { 2 - 3 } & Erkek & 48.6 \\
\hline \multirow{3}{*}{ Yaş } & 3 & 21,6 \\
\cline { 2 - 3 } & 4 & 46 \\
\cline { 2 - 3 } & 5 & 32,4 \\
\hline
\end{tabular}


Çalışmanın üçüncü aşamasını göstergebilimsel analiz çalışması oluşturmaktadır. Belirlenen 10 model sallanan at, ilk olarak Charles Sanders Peirce'in geliştirdiği ve O' Neill'in ürün analizinde kullandığı gösterge sistemi üzerinden analiz edilmiştir. Peirce'1n gösterge türlerini O’Neill endüstriyel ürünlerin analizinde kullanılmak üzere görüntüsel gösterge türlerini, form geleneği, renk, materyal, metafor, tarz ve çevre; belirtisel gösterge türlerini işaretleme biçimleri, 1şık ve ses, gürültü, koku, dokunma ve grafik şekiller; simgesel gösterge türlerini de grafik simge, simgesel renk ve simgesel biçim olarak belirlemiştir. Sallanan ata binildiğinde oyuncağın salınımına bağlı olarak bir ses çıkmaktadır. Fakat bu ses oyuncağın bulunduğu zemine göre değişiklik göstermektedir. Çalışmada öngörülen analiz yönteminde deneyimleme söz konusu olmadığından malzemeden kaynaklı koku da göz ardı edilmiştir. Buna bağlı olarak 1şık, ses, gürültü ve koku gibi göstergeler analiz kapsamı dışında tutulmuştur. (T. 6)

Tablo 6. Ürün Analizinde Kullanılacak Olan Gösterge Türleri

\begin{tabular}{|c|c|c|}
\hline \multicolumn{3}{|c|}{ Gösterge Türleri } \\
\hline Görüntüsel & Belirtisel & Simgesel \\
\hline Form geleneği & İşaretleme biçimleri & Grafik simgeler \\
\hline Renk & Dokunma & Simgesel renkler \\
\hline Materyal & Grafik şekiller & Simgesel biçimler \\
\hline Metafor & & \\
\hline Tarz & & \\
\hline Çevre & & \\
\hline
\end{tabular}

\section{Bulgular ve Değerlendirme}

Çalışmada elde edilen bulgular iki grupta ele alınmıştır. Birincisi anket sonuçlarından elde edilen bulgular olup analiz çalışmasına buradan elde edilen verilerin bir kısmı altlık oluşturmuştur. İkincisi de O'Neill'in belirlediği gösterge türlerine göre yapılan analiz çalışmasından elde edilen bulgulardır. Çalışma modellerin deneyimlenmesi üzerine kurgulanmadığı ve anket çocuklara fotoğraflar üzerinden uygulandığı için analizde yer alan maddelerin bir kısmı yazarlar tarafından yorumlanmıştır.

Anket sonuçlarından elde edilen verilere göre katılımcıların \%39'u sallanan at oyuncağına sahiptir. \%54'lük kısmı daha önce sallanan atı deneyimlemiştir. Kat1lımcılara gösterilen oyuncağa sahip olmak isteyip istemedikleri sorulduğunda büyük çoğunlukla evet cevabı alınmıştır.

Katılımcılar No: 24 kodlu oyuncağı büyük çoğunlukla (\%79 oranında) ata benzetmişlerdir. Aynı oyuncağı katılımcıların küçük bir kısmı gemiye benzetirken benzetme yapılan diğer nesneler de motosiklet, sehpa, otobüs, puzzle ve tepedir. Benzetme yapılmayan duruma rastlanmamıştır.

No: 27 kodlu oyuncak çoğunlukla (\%27) ata benzetilmiştir. Bisiklet (\%11), motosiklet $(\% 8)$ ve araba $(\% 5)$ tekrar edilen diğer cevaplardır. Ayrıca cevaplar arasında 
say1, sandalye, salıncak, kalorifer, kızak gibi nesnelerle koyun, köpek, inek, geyik, fil, ördek, tavşan gibi hayvanlar yer almaktadır. Katılımcıların bir kısmı da oyuncağı herhangi bir şeye benzetememiştir. Bu oyuncakta benzetilen nesneler daha çok farklılaşmış olup bu durumu oyuncağın soyut biçimiyle açıklamak mümkündür. Genelde binme işleviyle ilişkilendirdikleri görülmektedir.

No: 29 kodlu oyuncak katılımcılara sorulduğunda birçok farklı nesneyle benzerlik ilgisi kurulduğu görülmüştür. Bunlardan araba \%18'lik oranıyla ön plana çıkmıştır. İkinci olarak da at (\%10.5), kızak (\%10.5) ve sandalye (\%8) cevapları dikkat çekmektedir. Bunun dişında salıncak, köpek, kedi, koyun, unicorn (boynuzlu at), zebra, fil, oyuncak kutusu, banyo, ev, eyer, tuvalet gibi kavramlar yanıtlar arasında yer almaktadır. Katılımcıların küçük bir kısmı gösterilen oyuncağı herhangi bir şeye benzetememiştir. Benzerlik ilgisi kurulan nesnelerin çeşitliliği, bu oyuncağın formunun soyut olmasıyla ilişkilendirilebilir.

No: 32 kodlu oyuncak için at ve bisiklet (\%13) benzetmeleri en çok verilen cevaplar arasındadır. Daha sonra araba (\%8), motosiklet (\%8) ve k1zak (\%8) cevaplar1 gelmektedir. Cevaplar arasında salyangoz, top, karınca, kedi, ayı, kurbağa, gemi, sandalye, salıncak, kaydırak ve kemer birer kez söylenmiştir. Çocukların çoğunun sahip olmak istemedikleri oyuncağın da 32 kodlu oyuncak olduğu tespit edilmiştir. \%13'lük bir kısmı da oyuncağı herhangi bir şeye benzetememiştir. Verilen cevaplara göre çocukların binme işlevine bağlı kalarak benzetme yaptıkları söylenebilir.

No: 34 kodlu oyuncakla ilgili olarak en yoğun alınan cevap (\%10) çocukların oyuncağ1 hiçbir şeye benzetememesi olmuştur. \%8'lik oranla vites en yoğun benzetilen nesne olmuştur. Soyut bir forma sahip olan oyuncak at, civciv, inek, koltuk, gemi, bot, tekerlek, makina, demir, kurşun asker, çekirdek gibi nesne ve hayvanlara benzetilmiştir. Kırmızı küreye sahip tutacağa sahip olan oyuncağın bu biçimden dolayı ok, kırmızı 1şık, oyun konsolu, düğme, lolipop gibi nesnelerle ilgisinin kurulduğunu söylemek mümkündür.

No: 36 için benzetilen nesne açısından en yoğun tespit edilen cevaplar tahterevalli (\%18) ve hiçbir şey (\%18)'dir. Bunların dışında yatak, araba, at, dalga ve sandalye cevapları daha az oranla tekrar etmiştir. Zürafa, keçi, fil, balık, kuzu gibi hayvanlar ile yol, gemi, tuvalet, salıncak gibi nesnelere de benzetildiği görülmüştür.

No:40 kodlu oyuncak en çok yatağa (\%18) benzetilmiştir. İkinci olarak araba $(10,5)$ cevabı verililmiştir. Daha sonra salıncak, fil ve bebek cevapları tercih edilmiştir. Ayrıca tahterevalli, tekerlek, dolap, yatak, koltuk, kumanda, pusula, bisiklet, deniz, su, at, kuzu ve pegasus (kanatlı at) da verilen cevaplar arasındadir. Çocukların verdiği cevaplardan su ve deniz ilgisini renk bağlamında kurdukları anlaşılmaktadır. 
No: 43 kodlu oyuncak (\%68) ağırlıklı olarak kuzuya, daha az oranlarda maymun, at, fare gibi hayvanlara benzetilmiştir. Yatak, robot, motosiklet, salıncak verilen diğer cevaplar arasındadır. Burada renk ve dokuya bağlı olarak çocukların yorumlarını yaptı̆̆ 1 söylenebilir.

No: 45 için en yoğun olarak (\%42) ay cevabı verilmiştir. İkinci olarak kuş, tavuk ve at (\%8), üçüncü olarak da karga ve yatak (\%5) cevapları verilmiştir. Bu cevaplardan da renk algısının etkili olduğunu söylemek mümkündür.

No:46 kodlu oyuncak için katılımcıların büyük çoğunluğu (\%84) bulut cevabını vermiştir. Farklı olarak kuzu, uğur böceği, at ve salıncak yanıtları alınmıştır.

Literatürden elde edilen 10 model sallanan at anket dışında O' Neill'in ürün analizinde kullandığı gösterge türlerinden yola çıkarak analiz edilmiştir. Analiz çalışmasından elde edilen bulgular aşağıdaki tabloda gösterilmiştir. (T. 7)

Tablo 7. Sallanan Atların Analizi

\begin{tabular}{|c|c|c|c|c|c|}
\hline & ÜRÜN NO & NO: 24 & NO: 27 & NO: 29 & NO: 32 \\
\hline & Gösterge Türleri & & & & \\
\hline & & (URL-1) & (URL-2) & (URL-3) & (URL-4) \\
\hline & Form geleneği & Somut Biçim & Somut Biçim & Soyut Biçim & Soyut Biçim \\
\hline & Renk & Huş ve kahverengi & Huş ve kırmızı & Huş & Huş ve kırmızı \\
\hline$\overline{\mathscr{g}}$ & Materyal & Ahşap & Ahşap & Ahşap & Ahşap \\
\hline $\mid$ & Metafor & At & At, bisiklet, araba & Araba, at, kızak & \begin{tabular}{|l|}
$\begin{array}{l}\text { At, bisiklet, } \\
\text { motosiklet }\end{array}$ \\
\end{tabular} \\
\hline ن & Tarz & Modern & Modern & Modern & Modern \\
\hline & Çevre & $\begin{array}{l}\text { Her iç mekana } \\
\text { uygun }\end{array}$ & $\begin{array}{l}\text { Her iç mekana } \\
\text { uygun }\end{array}$ & $\begin{array}{l}\text { Her iç mekana } \\
\text { uygun }\end{array}$ & $\begin{array}{l}\text { Her iç mekana } \\
\text { uygun }\end{array}$ \\
\hline$\overline{\mathscr{D}}$ & $\begin{array}{l}\text { İşaretleme } \\
\text { biçimleri }\end{array}$ & $\begin{array}{l}\begin{array}{l}\text { Ürünün kullanım } \\
\text { biçimine işaret } \\
\text { eder }\end{array} \\
\end{array}$ & $\begin{array}{l}\begin{array}{l}\text { Ürünün kullanım } \\
\text { biçiminine işaret } \\
\text { eder }\end{array} \\
\end{array}$ & $\begin{array}{l}\text { Ürünün kullanım } \\
\text { biçimine işaret } \\
\text { eder }\end{array}$ & $\begin{array}{l}\text { Ürünün kullanım } \\
\text { biçimine işaret } \\
\text { eder }\end{array}$ \\
\hline ตั: & Dokunma & Sert doku & Sert doku & Sert doku & Sert doku \\
\hline & Grafik şekiller & Yok & Yok & Yok & Yok \\
\hline & Grafik simgeler & Yok & Yok & Yok & Yok \\
\hline 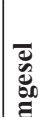 & Simgesel renkler & $\begin{array}{l}\text { Tutacağı ve oturma } \\
\text { alanını simgeleyen } \\
\text { kahverengi }\end{array}$ & $\begin{array}{l}\text { Tutacağı ve oturma } \\
\text { alanını simgeleyen } \\
\text { kırmızı }\end{array}$ & Yok & $\begin{array}{l}\text { Tutacağı ve oturma } \\
\text { alanını simgeleyen } \\
\text { kırmızı }\end{array}$ \\
\hline 涪 & Simgesel biçimler & $\begin{array}{l}\text { Sallanma, binme, } \\
\text { oturma işlevini } \\
\text { simgeleyen biçim }\end{array}$ & $\begin{array}{l}\text { Sallanma işlevini } \\
\text { simgeleyen biçim }\end{array}$ & $\begin{array}{l}\text { Binme, sallanma, } \\
\text { oturma işlevini } \\
\text { simgeleyen biçim }\end{array}$ & $\begin{array}{l}\text { Binme, sallanma } \\
\text { işlevini simgeleyen } \\
\text { biçim }\end{array}$ \\
\hline
\end{tabular}




\begin{tabular}{|c|c|c|c|c|c|}
\hline \multicolumn{2}{|c|}{ ÜRÜN NO } & NO:34 & NO: 36 & NO: 40 & NO: 43 \\
\hline \multicolumn{6}{|c|}{ Gösterge Türleri } \\
\hline & & (URL-5) & (URL-6) & (URL-7) & (URL-8) \\
\hline \multirow{6}{*}{ 胥 } & Form geleneği & Soyut Biçim & Soyut Biçim & Soyut Biçim & Somut Biçim \\
\hline & Renk & Kayın ve kırmızı & Kayın ve kırmızı & $\begin{array}{l}\text { Mavi, huş ve } \\
\text { kırmızı }\end{array}$ & Beyaz, huş \\
\hline & Materyal & Ahşap & Ahşap & $\begin{array}{l}\text { Ahşap, sünger, } \\
\text { kumaş }\end{array}$ & $\begin{array}{l}\text { Ahşap, sünger, } \\
\text { kumaş }\end{array}$ \\
\hline & Metafor & Vites, ok, lolipop & $\begin{array}{l}\text { Tahterevalli, yatak, } \\
\text { araba }\end{array}$ & $\begin{array}{l}\text { Yatak, araba, } \\
\text { salıncak }\end{array}$ & Kuzu \\
\hline & Tarz & Modern & Modern & Modern & Modern \\
\hline & Çevre & $\begin{array}{l}\text { Her iç mekana } \\
\text { uygun }\end{array}$ & $\begin{array}{l}\text { Her iç mekana } \\
\text { uygun }\end{array}$ & $\begin{array}{l}\text { Her iç mekana } \\
\text { uygun }\end{array}$ & $\begin{array}{l}\text { Her iç mekana } \\
\text { uygun }\end{array}$ \\
\hline \multirow{3}{*}{ 赵 } & $\begin{array}{l}\text { İşaretleme } \\
\text { biçimleri }\end{array}$ & $\begin{array}{l}\text { Ürünün kullanım } \\
\text { biçimine işaret } \\
\text { eder }\end{array}$ & $\begin{array}{l}\text { Ürünün kullanım } \\
\text { biçimine işaret } \\
\text { eder }\end{array}$ & $\begin{array}{l}\text { Ürünün kullanım } \\
\text { biçimine işaret } \\
\text { eder }\end{array}$ & $\begin{array}{l}\text { Ürünün kullanım } \\
\text { biçimine işaret eder }\end{array}$ \\
\hline & Dokunma & Sert doku & Sert doku & $\begin{array}{l}\text { Yumuşak ve sert } \\
\text { doku }\end{array}$ & Yumuşak doku \\
\hline & Grafik şekiller & Yok & Yok & Yok & Yok \\
\hline \multirow{3}{*}{ 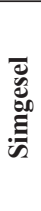 } & Grafik simgeler & Yok & Yok & Yok & Yok \\
\hline & Simgesel renkler & $\begin{array}{l}\text { Tutacağı } \\
\text { simgeleyen kırmız1 }\end{array}$ & $\begin{array}{l}\text { Tutacağı } \\
\text { simgeleyen kırmızı }\end{array}$ & $\begin{array}{l}\text { Tutacağ } 1 \\
\text { simgeleyen kırmızı }\end{array}$ & $\begin{array}{l}\text { Kuzuyu simgeleyen } \\
\text { beyaz renk }\end{array}$ \\
\hline & Simgesel biçimler & $\begin{array}{l}\text { Sallanma, binme } \\
\text { işlevini simgeleyen } \\
\text { biçim }\end{array}$ & Yok & $\begin{array}{l}\text { Sallanma, yatma } \\
\text { işlevini simgeleyen } \\
\text { biçim }\end{array}$ & $\begin{array}{l}\text { Sallanma işlevini } \\
\text { simgeleyen biçim }\end{array}$ \\
\hline
\end{tabular}

\begin{tabular}{|c|c|c|c|}
\hline & URÜN NO & NO:45 & NO: 46 \\
\hline & terge Türleri & & \\
\hline & & (URL-9) & (URL-10) \\
\hline & Form geleneği & Somut Biçim & Somut Biçim \\
\hline $\bar{\Phi}$ & Renk & Siyah, huş & Gri, huş \\
\hline 跑 & Materyal & Ahşap, sünger, kumaş & Ahşap, sünger, kumaş \\
\hline 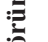 & Metafor & Ay & Bulut \\
\hline & Tarz & Modern & Modern \\
\hline & Çevre & Her iç mekana uygun & Her iç mekana uygun \\
\hline$\overline{\mathscr{D}}$ & $\begin{array}{l}\text { İşaretleme } \\
\text { biçimleri }\end{array}$ & $\begin{array}{l}\text { Ürünün kullanım } \\
\text { biçimine işaret eder }\end{array}$ & $\begin{array}{l}\text { Ürünün kullanım } \\
\text { biçimine işaret eder }\end{array}$ \\
\hline 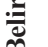 & Dokunma & Yumuşak doku & Yumuşak doku \\
\hline & Grafik şekiller & Yok & Yok \\
\hline & $\begin{array}{l}\text { Grafik } \\
\text { simgeler }\end{array}$ & Yok & Yok \\
\hline 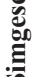 & $\begin{array}{l}\text { Simgesel } \\
\text { renkler }\end{array}$ & Tutacağ 1 simgeleyen huş & Tutacağı simgeleyen huş \\
\hline & $\begin{array}{l}\text { Simgesel } \\
\text { biçimler }\end{array}$ & $\begin{array}{l}\text { Atın ayaklarına } \\
\text { gönderme yapan biçim }\end{array}$ & $\begin{array}{l}\text { Atın ayaklarına } \\
\text { gönderme yapan biçim }\end{array}$ \\
\hline
\end{tabular}


Görüntüsel gösterge türlerinden form geleneği soyut ve somut anlatım olarak tanımlanmıştır. Bir nesneyle net olarak benzerlik ilişkisi kurulan biçimler somut, diğerleri de soyut olarak nitelendirilmiştir. Anketlerden elde edilen bulgular bu tanımlamay1 destekleyecek niteliktedir ve analize altlık oluşturmuştur. Renk, materyal, tarz ve çevre yazarlar tarafından yorumlanmıştır. Seçilen ürünler levha malzemenin büküm ve/veya kesim gibi işlemlerle şekillendirildiği için tarz göstergesi modern olarak tanımlanmıştır. Çevre olarak da her iç mekana uygun tanımlaması yapılmıştır. Metaforla ilgili veriler, anketlerden elde edilmiştir. Anket sonuçlarına göre en çok tekrar edilen cevaplara analizde yer verilmiştir. Buna bağlı olarak oyuncağın biçiminin soyut olmasının benzerlik ilgisi kurulan nesnelerin çeşitlenmesine neden olduğunu söylemek mümkündür. Gösterilen şekle at dışında araba, motosiklet, kızak gibi araçlar; vites, tahterevalli, salıncak, yatak gibi nesneler ve kuzu, ay, bulut ile çeşitli hayvan isimlerinin söylendiği tespit edilmiştir.

Belirtisel gösterge türlerinden işaretleme biçimleri, dokunma ve grafik şekilleri de yazarlar tarafindan yorumlanmıştır. Çalışmada modellerin deneyimlenmesi söz konusu olmadığ 1 ve çocukların bunları gördüğü fotoğraf üzerinden ifade edemeyeceklerinden dolayı veriler yazarlar tarafından yorumlanmıştır. Ürünlerin tamamının kullanım biçimine işaret ettiği tespit edilmiştir. Oyuncaklarda malzeme olarak ahşap ya da ahşap, sünger ve kumaşın bir arada kullanıldığı görülmüştür. Malzeme kullanımına bağlı olarak sert ve yumuşak dokulu oldukları belirlenmiştir. Oyuncaklarda herhangi bir grafik şekil tespit edilmemiştir.

Simgesel gösterge türlerinden simgesel biçim, anket cevapları üzerinden; grafik simge ve simgesel renk yazarlar tarafından belirlenmiştir. Simgesel renklerin genellikle oyuncak üzerinde yer alan tutma, ayak koyma, oturma işlevini vurgulamak amaçlı kullanıldığ1 görülmüştür. Bazı ürünlerde de renk algısı, çocuğun ürünü farklı şeylere benzetmesine neden olmuştur (mavi - dalga/ siyah - karga gibi). Çocuklar genellikle oyuncakların biçimlerini sallanma, binme, yatma ve oturma işleviyle ilişkilendirmiş ve bu da ürünün simgesel biçimini ifade etmiştir.

\section{Sonuç}

Bu çalışmada Sallanan At Oyuncağı'na, tasarım dili, tasarım biçimi üzerinden göstergebilimsel çözümleme yapılmıştır. Öncelikle çocukların oyuncağı nasıl anlamlandırdıkları belirlenmiş sonra da ürünün görüntüsel, belirtisel ve simgesel anlamı tartışmaya açılarak, ortaya koyduğu anlam değerlendirilmiştir. Literatürden elde edilen 10 model sallanan at anket ve analiz çalışmalarıyla değerlendirilmiştir. Değerlendirme sonucunda, oyuncağın görüntüsel olarak materyal, form, renk, metafor, tarz ve çevre gibi göstergeleri; belirtisel olarak işaret, dokunma ve grafiksel göstergeleri ve son olarak da simgesel olarak grafik, simgesel renk ve simgesel biçimleri ifade eden göstergeler anlamlandırılmıştır. 
Değnek at, ata binmekle bağdaştırılarak ortaya konmuş bir biçimdir. Daha sonra binmek işlevine sallanma işlevi eklenmiştir. At formu masif ahşabın oyma vb. üretim yöntemleriyle üçüncü boyuta ulaştırıldığı yek pare ürünlerde somut bir biçimde ele alındığg gibi, geleneksel biçimden uzaklaşarak dört bacaklı, yeleli, eyerli görüntüsünden sıyrılarak da biçimlenmektedir. Sallanan at oyuncağı anlamsal olarak da soyutlanmış, at formundan tamamen uzak biçimler meydana gelmiştir. Somut ya da soyut ürün biçimi genel olarak ürünün kullanım şeklini işaret etmektedir. Çocuğun hayal gücüne bağlı olarak oyuncak kimi zaman ata, kimi zaman araca, kimi zaman başka bir hayvana, kimi zaman da bambaşka bir nesneye (lolipop, vites, salıncak, yatak) dönüşebilmektedir. Ürünlerde farklı işlevler renklerin farklılaşmasıyla ifade edilmiştir. Genellikle tutma yerlerinin renklerinin farklılaştırılarak vurgulandığı görülmektedir. Bununla birlikte örneklerin bir kısmında oturma ve ayak koyma yerlerinde de farklı renk kullanımı dikkat çekmektedir. Bu da simgesel renk kullanımının işleve bağlı olarak şekillendiğini göstermektedir.

Çalışmanın sonucunda sallanan at figürünü ifade eden ve farklı biçimlere dönüşen oyuncağın, çocukların hayatında yer aldıkça, kurgulandığı farklı biçimsel anlamıyla çocukların hayal güçlerini artıran bir anlam beslediği ortaya çıkmaktadır.

Hakem Değerlendirmesi: Dış bağımsız.

Çıkar Çatışması: Yazarlar çıkar çatışması bildirmemiştir.

Finansal Destek: Yazarlar bu çalışma için finansal destek almadığını beyan etmiştir.

Peer-review: Externally peer-reviewed.

Conflict of Interest: The authors have no conflict of interest to declare.

Grant Support: The authors declared that this study has received no financial support.

\section{Kaynakça/References}

Ambeck Madsen, P. “Toys and Play.” The Danish Design Center Magazine 4 (1995): 3-20.

Bağlı, Hümanur. "Ürün Tasarımı Eğitiminde Kuram ve Uygulamanın Kesişmesi: Anlambilimsel Bir Deneme." UTAK 2014 Bildiri Kitabı, Der. Pınar Kaygan, Harun Kaygan. Ankara: ODTÜ Mimarlık Fakültesi Basım İşliği, 2014.

Bağl1, Hümanur. "Product Semantics Meet The User: A Design Workshop with a Fresh Look to an Old Paradigm." ITU AZ Journal 8 (2011): 103-121.

Bağlı, Hümanur. "Temsil Araçları Olarak Zanaat ve Tasarım: Turistik Nesneler Üzerine Kavramsal Bir Analiz.” Doktora tezi, İstanbul Teknik Üniversitesi, 2001.

Bayazıt, Nigan. Tasarımı Anlamak. İstanbul: İdeal Kültür Yayıncılık, 2008.

Bayrakçı, Oğuz, "Göstergebilimsel Araştırma Alanı Olarak Ürün Tasarımı.” Tasarım Kuram Dergisi (2011): 1-13.

Cinel Özyeşer, Nur. "Farklı SosyoEkonomik Düzeydeki 3-6 Yaş Grubu Çocuğu Olan Anne-Babaların Oyuncak ve Oyun Materyalleri Hakkındaki Görüşlerinin ve Bu Yaş Grubu Çocukların Sahip Oldukları Oyuncak ve Oyun Materyallerinin İncelenmesi.” Yüksek Lisans Tezi, Gazi Üniversitesi, 2006.

Eco, Umberto. Function and Sign: The Semiotic of Architecture. Sign, Symbol and Architecture. Ed.

Broadbent, G., Bunt, R., Jencks, C., New York: John Willey and Sons, 1979. 
Erkman, Fatma. Göstergebilime Giriş. İstanbul: Alan Yayıncılık, 1987.

Erkarslan, Önder. "Yeşil-Yeşilimsi: Ürün Göstergebilimi Aracılığıyla Sürdürülebilir Tasarım Uygulamalarının Eleştirisi.” Mimarlık Dergisi 349, (Eylül-Ekim 2009), erişim 2 Kasım 2018 http:// www.mimarlarodasi.org.tr/mimarlikdergisi.

Esin Düzakın ve Emre Güntürkün, "Yapı Oyuncaklarının Tarihsel Gelişimi”, Marmara Üniversitesi Sanat Tasartm Dergisi 8 (2017): 35- 42.

Krippendorf, K. Content Analysis, An Introduction to Its Methodology. Pennsylvania: Sage Publications, 1989.

Onur, Bekir. "Tarih Boyunca Oyun ve Oyuncaklar.” Ankara Üniversitesi Eğitim Bilimleri Fakültesi Dergisi 2 (1992): 365-386.

O'Neill, Shaleph. Comparing Compatible Semiotic Perspectives for the Analysis of Interactive Media Devices. Londra: Springer, 2005.

Peirce, Charles Sanders. Peirce on Signs: Writings on Semiotic. Der. James Hoopes. North Carolina: The University of North Caroline Press, 1994.

Piaget, Jean. Çocuğun Gözüyle Dünya. Çev İsmail Yergüz. Ankara: Dost Kitabevi, 2005.

Poyraz, Hatice. Okul Öncesi Dönemde Oyun ve Oyuncak. Ankara: Anı Yayıncılık, 1999.

Rüşvanlı, Hasan Ozan. "Türkiye'deki Oyuncak Sektöründe Yeni Ürün Tasarımını Tetikleyen Faktörler." Yüksek lisans tezi, İstanbul Teknik Üniversitesi, 2007.

Turan, Ahmet Zeki. “Tasarımda İletişim Sürecinin Oturma Elemanları Üzerinde İrdelenmesi.” Yüksek lisans tezi, İstanbul Teknik Üniversitesi, 2001.

Vihma, Susann. "Product Form-A Semiotic Approach. Semantic Visions in Design." Symposium on Design Research and Semiotics, 1990.

Yalçınkaya, Şengül. "Modern Kentin Yeni Kamusal Alanında Çocuk, Alışveriş Merkezleri ve Serbest Zaman Etkinlikleri,” İdealkent Dergisi 17 (2015): 80-105.

Yalçınkaya, Tosun. Eğitici Oyun ve Oyuncak Yapımı. İstanbul: Esin Yayınevi, 2004.

Yavuzer, Haluk. Çocuk Psikolojisi. İstanbul: Remzi Kitabevi, 2016.

Yengin, Deniz ve Bayrak, Tamer. “Tüketimin Oyunlaştırılmasıyla Artırılmış Gerçeklik,” Etkileşim Dergisi 1 (2018): 58-77.

https://www.contemporist.com/30-gift-ideas-for-modern-kids/modern-rocking-horse-131116-200-24/, Erişim 20.12.2018

http://atolyegalata.net/urun-kategori/ahsap-oyuncaklar/, Erişim 24.12.2018

https://www.muji.net/store/cmdty/detail/4548718596898?searchno=39, Erişim 06.01.2019

http://atolyegalata.net/urun/anaokulu-egitici-ahsap-oyuncak-2/, Erişim 24.12.2018

https://www.chairish.com/product/1367093/1960s-vintage-gloria-caranica-for-creative-playthingswooden-rocking-horse, Erişim 10.01.2019

https://www.handmadecharlotte.com/vintage-kids-amsterdam-modern/, Erişim 21.02.2019

https://www.furnituredesignkidspro.com, Erişim 20.12.2018

https://tr.pinterest.com/pin/37225134390134526/, Erişim 21.02.2019

https://www.designboom.com/design/maison-deux-updated-rocking-horse-iconic-moon-08-18-2017/, Erişim 21.02.2019

https://www.maisondeux.com/product/iconic-cloud/, Erişim 13.01.2019 